\title{
Standardized Expression of ${ }^{18}$ F-NAV4694 and ${ }^{11}$ C-PiB $\beta$-Amyloid PET Results with the Centiloid Scale
}

\author{
Christopher C. Rowe ${ }^{1,2}$, Gareth Jones ${ }^{1}$, Vincent Doré ${ }^{1,3}$, Svetlana Pejoska ${ }^{1}$, Laura Margison ${ }^{1}$, Rachel S. Mulligan ${ }^{1}$, \\ J. Gordon Chan ${ }^{1}$, Kenneth Young ${ }^{1}$, and Victor L. Villemagne ${ }^{1,2,4}$ \\ ${ }^{1}$ Department of Molecular Imaging, Austin Health, Melbourne, Australia; ${ }^{2}$ Department of Medicine, University of Melbourne, \\ Melbourne, Australia; ${ }^{3}$ CSIRO Health and Biosecurity, Brisbane, Australia; and ${ }^{4}$ Florey Institute of Neuroscience and Mental Health, \\ University of Melbourne, Melbourne, Australia
}

\begin{abstract}
A common quantitative output value for PET measures of $\beta$-amyloid $(A \beta)$ binding across tracers and methods would allow better comparison of data across sites and application of universal diagnostic and prognostic values. A method has recently been developed that generates a unit of measurement called the centiloid. We applied this method to 2-[2-18 F-fluoro-6-(methylamino)-3-pyridinyl]-1benzofuran-5-ol ( $\left.{ }^{18} \mathrm{~F}-\mathrm{NAV} 4694\right)$ and ${ }^{11} \mathrm{C}$-Pittsburgh compound $\mathrm{B}$ $\left({ }^{11} \mathrm{C}-\mathrm{PiB}\right) \mathrm{A} \beta$ images to derive the scaling factor required to express tracer binding in centiloids. Methods: Fifty-five participants, including 10 young controls (33 $\pm 7 \mathrm{y}$ old), underwent both ${ }^{11} \mathrm{C}-\mathrm{PiB}$ and ${ }^{18} \mathrm{~F}-\mathrm{NAV} 4694$ imaging no more than 3 mo apart, with the images acquired 50-70 min after tracer injection. The images were spatially normalized and analyzed using the standard centiloid method and regions (cortex and whole-cerebellum reference) downloaded from the Global Alzheimer Association Interactive Network website. Results: SUV ratios (SUVRs) showed a strong correlation in tracer binding $\left({ }^{18} \mathrm{~F}-\mathrm{NAV} 4694\right.$ SUVR $=1.09 \times{ }^{11} \mathrm{C}-\mathrm{PiB}$ SUVR $-0.08, R^{2}=$ 0.99). The equation to convert ${ }^{18} \mathrm{~F}-\mathrm{NAV} 4694$ to centiloids [100 $\times$ (18F-NAV4694 SUVR - 1.028)/1.174] was similar to a published equation for ${ }^{11} \mathrm{C}-\mathrm{PiB}\left[100 \times\left({ }^{11} \mathrm{C}-\mathrm{PiB}\right.\right.$ SUVR -1.009$\left.) / 1.067\right]$. In the young controls, the variance ratio $\left({ }^{18} \mathrm{~F}-\mathrm{NAV} 4694\right.$ centiloid SD divided by ${ }^{11} \mathrm{C}-\mathrm{PiB}$ centiloid SD) was 0.85 . Conclusion: The results for both ${ }^{11} \mathrm{C}-\mathrm{PiB}$ and ${ }^{18} \mathrm{~F}-\mathrm{NAV} 4694$ can now be expressed in centiloids, an important step that should allow better clinical and research use of $A \beta$ imaging. The standard centiloid method also showed that ${ }^{18} \mathrm{~F}-\mathrm{NAV} 4694$ has slightly higher $A \beta$ binding and lower variance than ${ }^{11} \mathrm{C}-\mathrm{PiB}$, important properties for detecting early $A \beta$ deposition and change over time.
\end{abstract}

Key Words: Alzheimer's disease; centiloid; amyloid imaging; betaamyloid; standardization

J Nucl Med 2016; 57:1233-1237

DOI: 10.2967/jnumed.115.171595

$\mathbf{T}$ here is wide variability in the numbers and methods used to report quantitative PET measures of $\beta$-amyloid $(A \beta)$ tracer binding in the brain (1). Results vary for each of the available tracers

Received Dec. 19, 2015; revision accepted Jan. 29, 2016.

For correspondence or reprints contact: Christopher C. Rowe, Department of Molecular Imaging, Austin Health, 145 Studley Rd., Heidelberg, Melbourne, Victoria 3084, Australia.

E-mail: Christopher.rowe@austin.org.au

Published online Feb. 16, 2016.

COPYRIGHT (c) 2016 by the Society of Nuclear Medicine and Molecular Imaging, Inc. because of differences in their specific and nonspecific binding properties and in their recommended reference regions (2-5). Results are also influenced by the timing of the acquisition after tracer administration, the duration of the acquisition, the image reconstruction algorithm used, whether partial-volume correction is applied, the choice and extent of cortical regions, and the type of quantitative method used, such as SUV ratio (SUVR), distribution volume ratio, or binding potential (6-16). Consequently, most imaging labs have had to derive a reference range for their method and tracers or rely on subjective visual interpretation.

This lack of consistency in image analysis methods and highly variable expression of the results impedes the pooling of data across sites and comparison of studies (17). Lack of standardization prevents the application of universal cut points for diagnostic and prognostic purposes (18) and limits comparison of the relative effectiveness of therapies that claim to reduce $A \beta$ burden (17).

An international working party of $A \beta$ imaging researchers has developed a method to standardize quantitative PET measures of $\mathrm{A} \beta$ binding by scaling the outcome to the centiloid scale (18). This scale has a zero-centiloid point that corresponds to the mean result from scans of young adults who, based on age, are reasonably assumed to be free of $A \beta$ plaques. The 100-centiloid point corresponds to the mean result from scans of patients with typical Alzheimer disease (AD) of mild severity, the AD stage at which $\mathrm{A} \beta$ burden peaks $(19,20)$. Consequently, the measurement unit has been named to reflect the 100-point scale and the application to amyloid, hence the term "centi-loid."

The data to convert ${ }^{11} \mathrm{C}-\mathrm{PiB} \mathrm{A} \beta$ PET results to centiloids are available on the Global Alzheimer Association Interactive Network website (GAAIN) (http://www.gaain.org). This website provides free access to a standard cortical volume of interest (VOI) that covers the areas of significant ${ }^{11} \mathrm{C}-\mathrm{PiB} \mathrm{A} \beta$ binding in $\mathrm{AD}$ (Fig. 1A) and a whole-cerebellum VOI (Fig. 1B) for use as the reference region. The standard cortical template was derived by subtracting a mean ${ }^{11} \mathrm{C}$-PiB image of older healthy subjects (normalized in Montreal Neurological Institute (MNI)-152 space with SPM8 [Wellcome Trust Centre for Neuroimaging]) from a mean ${ }^{11} \mathrm{C}-\mathrm{PiB}$ image of $\mathrm{AD}$ patients. The resultant subtraction VOI was smoothed and then subjected to a threshold that included only voxels with a difference of more than 1.05 SUVR units. This data-driven VOI includes frontal, temporal, parietal (including precuneus), cingulate, insular, and anterior striatal gray matter (Fig. 1A). The website supplies the linear equation that converts to centiloids the SUVR (obtained by the standard centiloid method) for any ${ }^{11} \mathrm{C}$-PiB scan acquired from 50 to $70 \mathrm{~min}$ after injection. A validation set of ${ }^{11} \mathrm{C}-\mathrm{PiB}$ scans and $\mathrm{MR}$ scans is also 


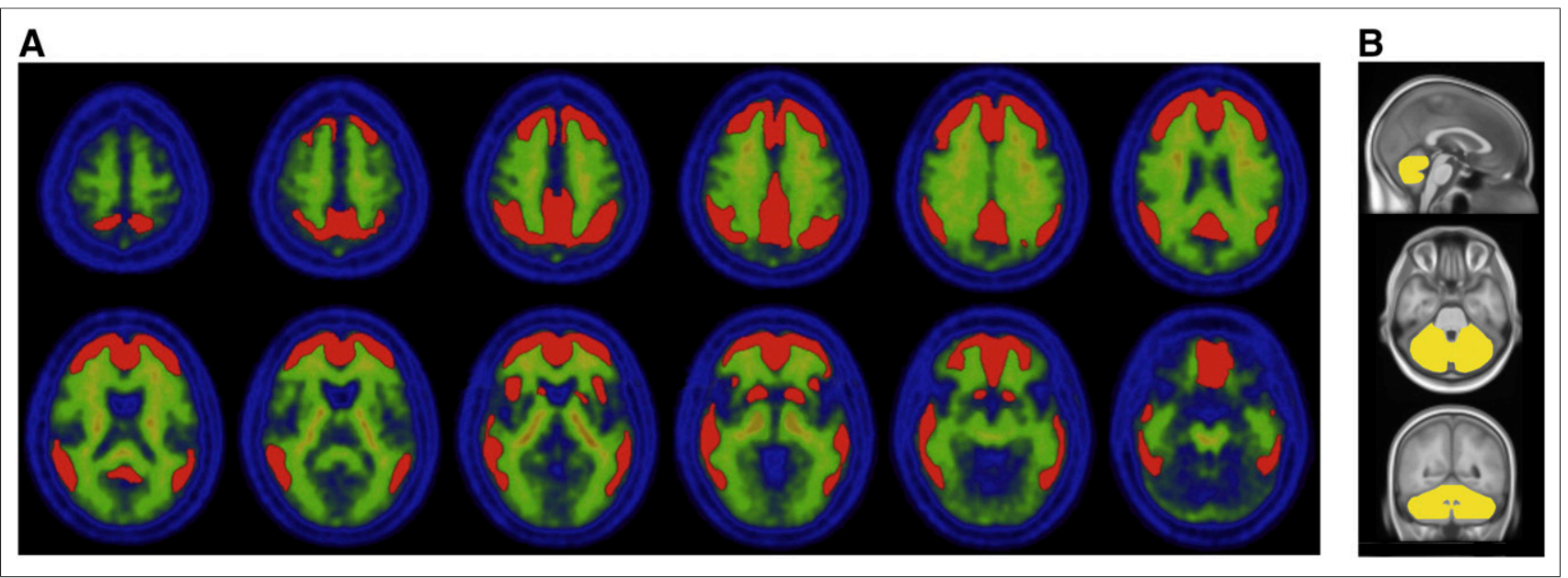

FIGURE 1. Standard centiloid method. (A) Cortical VOI normalized to MNI-152 space. (B) Whole-cerebellum reference region superimposed on MNI-152 MRI template. (Adapted with permission of (18).)

supplied. Users can confirm that they are applying the method correctly by comparing their own results for the validation scans to the results supplied with the validation scans before analyzing their own scans. It is then possible to derive an additional linear equation to convert the results from any in-house analysis method to centiloids by analyzing ${ }^{11} \mathrm{C}-\mathrm{PiB}$ images that have been converted to parametric centiloid images by the standard centiloid method (18).

To convert SUVR to centiloids for a tracer other than ${ }^{11} \mathrm{C}-\mathrm{PiB}$, a site must first obtain matching scans from the same individual using both ${ }^{11} \mathrm{C}-\mathrm{PiB}$ and the other tracer, according to the standard centiloid method described by Klunk et al. (18). The matching scans must cover the spectrum of $\mathrm{A} \beta$ tracer binding ranging from young controls to patients with mild AD. A linear conversion equation (scaling factor) is then derived from VOIs on these scans to express the results in centiloids. By uploading the matched scans to GAAIN, the site can make them available to other sites wishing to convert their own PET results to centiloids. Furthermore, the other sites can then display a range of their scans as parametric images in centiloids, apply their own in-house analysis method, and derive a second scaling factor that allows their own analysis method to convert the results directly into centiloids (18).

2-[2- ${ }^{18}$ F-fluoro-6-(methylamino)-3-pyridinyl]-1-benzofuran-5-ol $\left({ }^{18} \mathrm{~F}-\mathrm{NAV} 4694\right.$, formerly known as AZ4694) is an A $\beta$ imaging radiopharmaceutical that has imaging characteristics nearly identical to those of ${ }^{11} \mathrm{C}$-PiB but with the convenience of ${ }^{18} \mathrm{~F}$ labeling $(21,22)$. The steric structure is similar to that of ${ }^{11} \mathrm{C}-\mathrm{PiB}$ (Fig. 2), as are the time-activity curves and blood clearance rates (23). A head-to-head study on a range of healthy older individuals and patients with mild cognitive impairment and AD demonstrated that the images and neocortical SUVRs for ${ }^{18} \mathrm{~F}-\mathrm{NAV} 4694$ are nearly identical to those for ${ }^{11} \mathrm{C}-\mathrm{PiB}$ (24). Like ${ }^{11} \mathrm{C}-\mathrm{PiB},{ }^{18} \mathrm{~F}-\mathrm{NAV} 4694$ has higher specific cortical binding and lower nonspecific white matter binding than has been reported for other ${ }^{18} \mathrm{~F}$-labeled $\mathrm{A} \beta$ radiopharmaceuticals $(3,23,25,26)$.

In this article, we describe the data acquisition and derived scaling factor required to convert ${ }^{18} \mathrm{~F}-\mathrm{NAV} 4694$ SUVRs to centiloids.

\section{MATERIALS AND METHODS}

The study was approved by the institutional review board of Austin Health, and all subjects signed an informed consent form.

\section{Subjects}

Matching ${ }^{11} \mathrm{C}-\mathrm{PiB}$ and ${ }^{18} \mathrm{~F}-\mathrm{NAV} 4694$ PET scans were obtained for 55 subjects. The cohort comprised 10 young controls recruited specifically for this study and a previously published cohort of 25 elderly controls, 10 patients with mild cognitive impairment, 7 patients with mild $\mathrm{AD}$, and 3 patients with frontotemporal dementia (24). All subjects from the previously published cohort were included in this analysis. The demographics of the cohort are shown in Table 1 .

\section{Scanning}

The matching ${ }^{11} \mathrm{C}-\mathrm{PiB}$ and ${ }^{18} \mathrm{~F}-\mathrm{NAV} 4694 \mathrm{PET}$ scans for each individual were obtained within 3 mo of each other and with a minimum of $2 \mathrm{~h}$ between scans if ${ }^{11} \mathrm{C}-\mathrm{PiB}$ PET was done first or $24 \mathrm{~h}$ if ${ }^{18} \mathrm{~F}-\mathrm{NAV} 4694$ PET was done first. All scans were acquired on an Allegro PET camera (Philips) in 3-dimensional mode and were processed using a rotating ${ }^{137} \mathrm{Cs}$ point source for attenuation correction. Images were reconstructed using a 3-dimensional row-action maximum likelihood algorithm.

The participants were injected with $370 \mathrm{MBq}$ of ${ }^{11} \mathrm{C}-\mathrm{PiB}$ and $250 \mathrm{MBq}$ of ${ }^{18} \mathrm{~F}-\mathrm{NAV} 4694$. As per the centiloid standard protocol, the ${ }^{11} \mathrm{C}-\mathrm{PiB}$ acquisition was from 50 to $70 \mathrm{~min}$ after injection. Because this is also the optimal and recommended time for deriving SUVR with ${ }^{18}$ F-NAV4694 PET $(23,24)$, the same imaging window was used for both tracers. Examples of matching images with both tracers in a young control subject and a patient with mild AD are shown in Figure 3.

All subjects underwent MRI on a 3-T Trio camera (Siemens). A T1-weighted magnetization-prepared rapid gradient-echo sequence with $1 \times 1 \times 1.2 \mathrm{~mm}$ voxels was used for image registration. Partialvolume correction was not performed.

\section{Image Analysis}

Each subject's MR images were coregistered to the MNI-152 template using SPM8, and then each subject's PET images were coregistered via the derived MRI transformation parameters using the SPM8 unified segmentation method, as described in detail in the centiloid

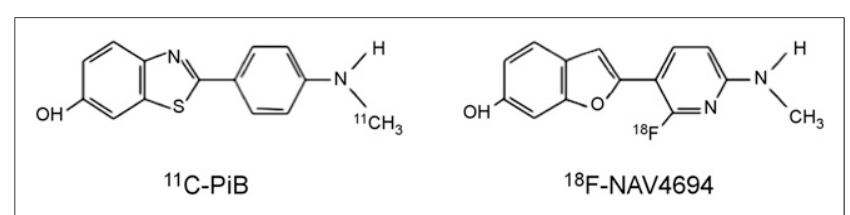

FIGURE 2. Chemical structures of ${ }^{11} \mathrm{C}-\mathrm{PiB}$ and ${ }^{18} \mathrm{~F}-\mathrm{NAV} 4694$. 
TABLE 1

Demographics

\begin{tabular}{lccc}
\hline \multicolumn{1}{c}{ Group } & $n$ & Age $(\mathrm{y})$ & MMSE \\
\hline Young controls & 10 & $33 \pm 7^{*}$ & $>28$ \\
\hline Elderly controls & 25 & $74 \pm 8$ & $29 \pm 1$ \\
$\begin{array}{l}\text { Patients with mild cognitive } \\
\text { impairment }\end{array}$ & 10 & $75 \pm 9$ & $27 \pm 3^{\star}$ \\
$\begin{array}{l}\text { Patients with AD } \\
\text { Patients with frontotemporal } \\
\text { dementia }\end{array}$ & 7 & $73 \pm 11$ & $24 \pm 2^{*}$ \\
\hline
\end{tabular}

*Significantly different from elderly controls $(P<0.05)$.

MMSE $=$ mini-mental state examination score.

Data are mean \pm SD.

methodology paper (18). The standard centiloid cortex and wholecerebellum reference VOIs were downloaded from GAAIN (Fig. 1) and applied to each scan.

The local processing pipeline was first validated on the standard set of ${ }^{11} \mathrm{C}$-PiB images obtained from GAAIN. Then, the matching ${ }^{11} \mathrm{C}-\mathrm{PiB}$ and ${ }^{18} \mathrm{~F}-\mathrm{NAV} 4694$ images were analyzed using the standard method and the centiloid templates from GAAIN to derive SUVR measures, which were plotted against each other. The resulting linear equation was used to convert the standard ${ }^{18} \mathrm{~F}-\mathrm{NAV} 4694$ SUVR to the equivalent, or "calculated," ${ }^{11} \mathrm{C}-\mathrm{PiB}$ SUVR that is, ${ }^{18} \mathrm{~F}-\mathrm{NAV} 4694$ SUVR $=m \times\left({ }^{11} \mathrm{C}-\mathrm{PiB}\right.$ SUVR $)+b$; so that, by rearrangement of the equation, calculated ${ }^{11} \mathrm{C}-\mathrm{PiB}$ SUVR $=\left({ }^{18} \mathrm{~F}-\mathrm{NAV} 4694 \mathrm{SUVR}-b\right) / m$.

As per the standard method, ${ }^{18} \mathrm{~F}-\mathrm{NAV} 4694$ SUVR was first converted to calculated ${ }^{11} \mathrm{C}-\mathrm{PiB}$ SUVR, and then calculated ${ }^{11} \mathrm{C}-\mathrm{PiB}$ SUVR was converted to centiloids.

Finally, the equation to directly convert ${ }^{18} \mathrm{~F}-\mathrm{NAV} 4694$ SUVR to centiloids was derived by plotting ${ }^{18} \mathrm{~F}-\mathrm{NAV} 4694$ SUVR against the centiloids derived via conversion to calculated ${ }^{11} \mathrm{C}-\mathrm{PiB}$ SUVR.

The mean and variance of the ${ }^{11} \mathrm{C}-\mathrm{PiB}$ and ${ }^{18} \mathrm{~F}-\mathrm{NAV} 4694$ centiloids were compared in the young controls, and the variance ratio was expressed as the ${ }^{18} \mathrm{~F}-\mathrm{NAV} 4694$ centiloid SD divided by the ${ }^{11} \mathrm{C}-\mathrm{PiB}$ centiloid SD.

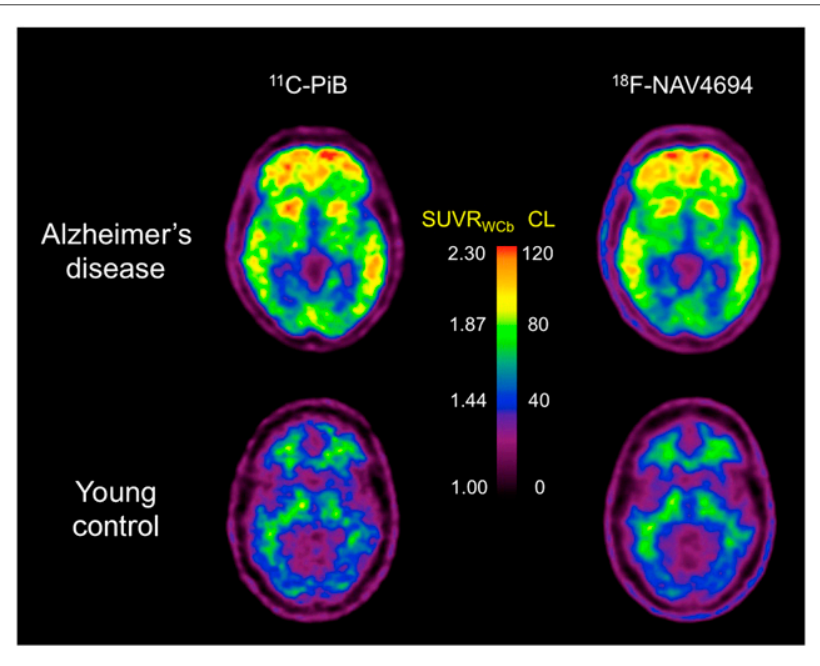

FIGURE 3. ${ }^{11} \mathrm{C}-\mathrm{PiB}$ and ${ }^{18} \mathrm{~F}-\mathrm{NAV} 4694$ images of mild-AD patient and young control. Color scale is set to SUVR units (calculated using standard centiloid method with whole-cerebellum [WCb] reference region) and to matching centiloid $(\mathrm{CL})$ units.

\section{RESULTS}

Validation of our local Austin Health implementation of the standard centiloid method using ${ }^{11} \mathrm{C}-\mathrm{PiB}$ scans from GAAIN gave a linear fit of Austin centiloids $=1.00 \times$ GAAIN centiloids -0.07 , with $R^{2}=0.9999$. The fit exceeded the minimum specified acceptance criteria (i.e., $R^{2}>0.98$; slope, 0.98-1.02; intercept, between -2 and +2$)(18)$, confirming that our implementation of the method was accurate.

The locally acquired matching ${ }^{11} \mathrm{C}-\mathrm{PiB}$ and ${ }^{18} \mathrm{~F}-\mathrm{NAV} 4694 \mathrm{im}-$ ages were then analyzed with the standard centiloid templates and method and demonstrated a close linear correlation: ${ }^{18} \mathrm{~F}-\mathrm{NAV} 4694$ SUVR $=1.09 \times{ }^{11} \mathrm{C}-\mathrm{PiB}$ SUVR $-0.08, R^{2}=0.99$ (Fig. 4). This satisfied the criterion that the correlation between tracers be greater than 0.70 to be valid for the centiloid process.

${ }^{18}$ F-NAV4694 SUVR was converted to the equivalent ${ }^{11} \mathrm{C}-\mathrm{PiB}$ SUVR using the above equation, and those results were then transformed to centiloids (Fig. 5). From these data, the linear equation required to directly convert ${ }^{18} \mathrm{~F}-\mathrm{NAV} 4694$ binding to centiloids was $100 \times\left({ }^{18} \mathrm{~F}-\mathrm{NAV} 4694 \mathrm{SUVR}-1.028\right) / 1.174$.

The mean and variance in the young controls were $-3.8 \pm 3.7$ centiloids for ${ }^{18} \mathrm{~F}-\mathrm{NAV} 4694$ and $-3.4 \pm 4.34$ centiloids for ${ }^{11} \mathrm{C}-\mathrm{PiB}$, yielding a variance ratio of 0.85 .

\section{DISCUSSION}

The study demonstrated that the A $\beta$ imaging tracer ${ }^{18} \mathrm{~F}-\mathrm{NAV} 4694$ has binding properties that allow conversion of SUVR output to centiloids by linear transformation. The linear equation we derived enables the results of ${ }^{18} \mathrm{~F}-\mathrm{NAV} 4694$ scans acquired 50-70 min after tracer injection and analyzed by the standard centiloid method to be converted to centiloids without the need to collect matching ${ }^{11} \mathrm{C}-\mathrm{PiB}$ scans. Other sites may now apply this equation and method to their own ${ }^{18} \mathrm{~F}-\mathrm{NAV} 4694$ scans. The standard centiloid method uses widely available, public domain programs to facilitate the conversion. The ${ }^{18} \mathrm{~F}-\mathrm{NAV} 4694$ and matched ${ }^{11} \mathrm{C}-\mathrm{PiB}$ scans used in this analysis have been uploaded to the centiloid site on GAAIN to serve as a validation dataset for other users.

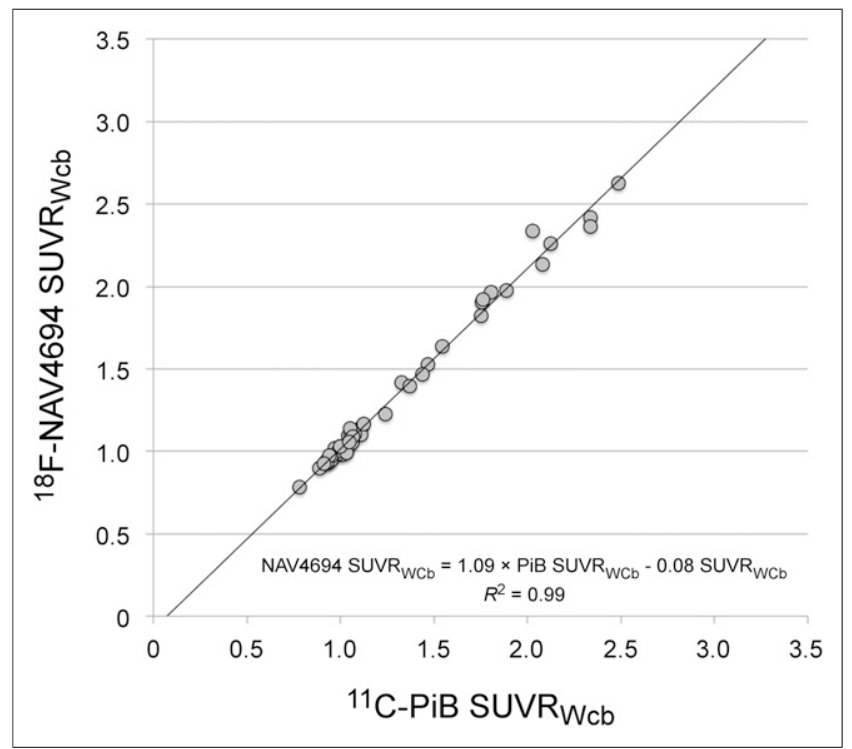

FIGURE 4. Plot of matching ${ }^{11} \mathrm{C}-\mathrm{PiB}$ SUVR and ${ }^{18} \mathrm{~F}-\mathrm{NAV} 4694$ SUVR for each subject. SUVR was calculated using standard centiloid method with whole-cerebellum (WCb) reference region. 


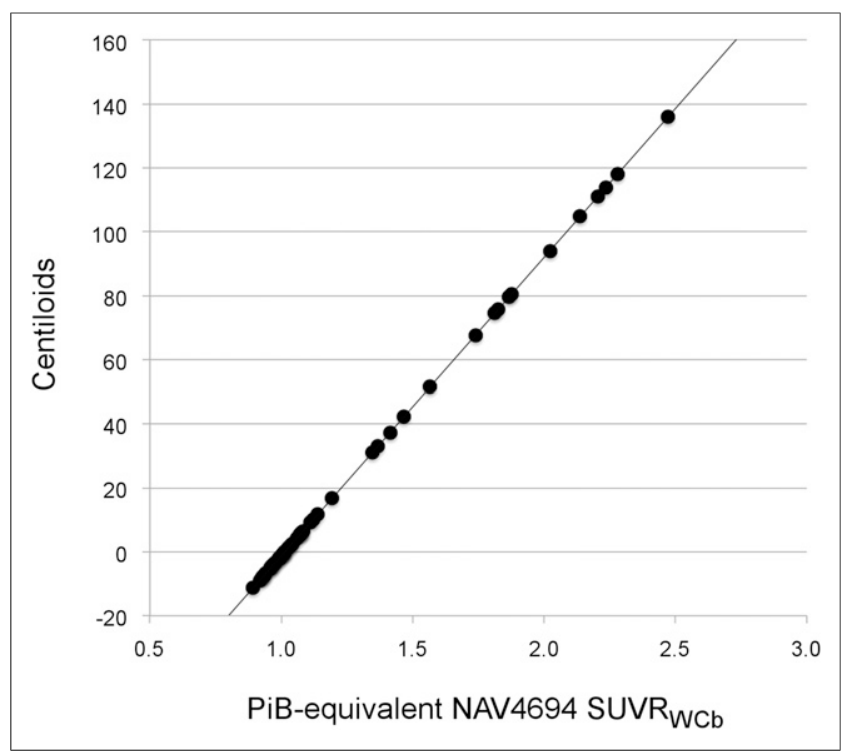

FIGURE 5. Plot of ${ }^{11} \mathrm{C}-\mathrm{PiB}$-equivalent ${ }^{18} \mathrm{~F}-\mathrm{NAV} 4694$ SUVR against centiloid value for each ${ }^{11} \mathrm{C}$-PiB SUVR. Good spread of data points is seen across centiloid range. SUVR was calculated using standard centiloid method with whole-cerebellum (WCb) reference region.

An additional benefit of the standard centiloid method is that it provides a standardized mechanism for comparing $\mathrm{A} \beta$ tracers against ${ }^{11} \mathrm{C}-\mathrm{PiB}$. The tight correlation between ${ }^{18} \mathrm{~F}-\mathrm{NAV} 4694$ and ${ }^{11} \mathrm{C}-\mathrm{PiB}$ binding $\left(R^{2}=0.99\right)$ and the slope of their plot $\left({ }^{18} \mathrm{~F}-\mathrm{NAV} 4694 \mathrm{SUVR}=1.09 \times{ }^{11} \mathrm{C}-\mathrm{PiB}\right.$ SUVR -0.08$)$ reveal that binding of ${ }^{18} \mathrm{~F}-\mathrm{NAV} 4694$ to $\mathrm{A} \beta$ is similar to-even slightly higher than-binding of ${ }^{11} \mathrm{C}-\mathrm{PiB}$ to $\mathrm{A} \beta$. In the young controls, the variation in binding was also lower for ${ }^{18} \mathrm{~F}-\mathrm{NAV} 4694$ than for ${ }^{11} \mathrm{C}-\mathrm{PiB}$, possibly because the ${ }^{18} \mathrm{~F}$ radiolabel on NAV4694 has a longer half-life (109 $\mathrm{min})$ than the ${ }^{11} \mathrm{C}$ radiolabel on PiB (20 min), resulting in a higher counting rate during the scanning window and better images. These findings suggest that the longer-half-life ${ }^{18} \mathrm{~F}$-labeled NAV4694 not only may have the advantage of efficient production and use but also may be better able to detect early $A \beta$ accumulation and small changes over time.

This study has not addressed the issue of regional tracer binding. However, it is expected that regional centiloid values can be derived by creating centiloid parametric images using the global centiloid transformation before applying VOIs. The value obtained from the voxels in a VOI would then be in centiloids.

Ideally, a site will reprocess its ${ }^{18} \mathrm{~F}-\mathrm{NAV} 4694$ images using the standard centiloid method and apply the conversion equation provided here to quantify the results in centiloids. However, it may be possible to globally convert a local-method SUVR directly to centiloids by analyzing the standard ${ }^{18}$ F-NAV4694 dataset we placed on GAAIN. Provided there is a good correlation with the standard centiloid templates for these images $\left(R^{2}>0.7\right)(18)$, centiloid parametric images generated by the standard centiloid method and regions can be used to derive a further linear transformation permitting the locally preferred analysis method to express the results directly in centiloids.

In this study population, the mean ${ }^{11} \mathrm{C}-\mathrm{PiB}$ value in young controls was -3.4 centiloids, slightly below the anticipated mean of zero. This result may be due to random variations in the study population or to variations in our imaging equipment or image reconstruction methods. In either case, because the effect was common to both the ${ }^{11} \mathrm{C}-\mathrm{PiB}$ images and the ${ }^{18} \mathrm{~F}-\mathrm{NAV} 4694 \mathrm{im}-$ ages, it should have had no impact on calculation of the conversion equation. However, differences in PET systems and reconstruction methods between our site and other sites might have a slight effect on use of the conversion equation at other sites. Further work is needed to identify whether equipmentspecific equations may be needed.

\section{CONCLUSION}

The standard centiloid method for quantification of A $\beta$ PET results should support better clinical and research use of $A \beta$ imaging. By providing cut-points that are applicable to all $\mathrm{A} \beta$ scans, the method will allow the use of multiple $A \beta$ tracers in multicenter, anti-A $\beta$ therapeutic trials and provide better diagnostic and prognostic data to clinicians. Both ${ }^{11} \mathrm{C}-\mathrm{PiB}$ and ${ }^{18} \mathrm{~F}-\mathrm{NAV} 4694$ measures of $A \beta$ burden can now be expressed in centiloids, and the conversion equations for other tracers are expected to become available soon.

\section{DISCLOSURE}

The costs of publication of this article were defrayed in part by the payment of page charges. Therefore, and solely to indicate this fact, this article is hereby marked "advertisement" in accordance with 18 USC section 1734. Cristopher Rowe has received research grants for imaging in dementia from Bayer-Schering Pharma, Avid Radiopharmaceuticals, GE Healthcare, Piramal, Astra Zeneca, and Navidea. He has been a consultant or paid speaker at sponsored conference sessions for Bayer-Schering Pharma, Piramal, GE Healthcare, Astra Zeneca, Roche, and Janssen. Victor Villemagne has been a consultant or paid speaker at sponsored conference sessions for Bayer-Schering Pharma, Piramal, GE Healthcare, Astra Zeneca, and Novartis. The study was partially supported by grants 1044361 and 1071430 from the National Health Medical Research Council (NHMRC) of Australia and by a research grant for imaging in dementia from Navidea. The funding sources had no input into the design or conduct of the study; the collection, management, analysis, or interpretation of the data; the preparation, review, or approval of the manuscript; or the decision to submit the manuscript for publication. No other potential conflict of interest relevant to this article was reported.

\section{ACKNOWLEDGMENTS}

We thank Prof. Michael Woodward, Dr. John Merory, Fiona Lamb, and the Brain Research Institute for their assistance with this study.

\section{REFERENCES}

1. Rowe CC, Villemagne VL. Brain amyloid imaging. J Nucl Med. 2011;52:17331740 .

2. Clark CM, Pontecorvo MJ, Beach TG, et al. Cerebral PET with florbetapir compared with neuropathology at autopsy for detection of neuritic amyloid-beta plaques: a prospective cohort study. Lancet Neurol. 2012;11:669-678.

3. Rowe CC, Ackerman U, Browne W, et al. Imaging of amyloid beta in Alzheimer's disease with ${ }^{18} \mathrm{~F}-\mathrm{BAY} 94-9172$, a novel PET tracer: proof of mechanism. Lancet Neurol. 2008;7:129-135.

4. Rowe $\mathrm{CC}, \mathrm{Ng} \mathrm{S}$, Ackermann U, et al. Imaging beta-amyloid burden in aging and dementia. Neurology. 2007;68:1718-1725. 
5. Thurfjell L, Lundqvist R, Buckley C, Smith A, Sherwin P. Automated quantification of $\left[{ }^{18} \mathrm{~F}\right]$ flutemetamol data: comparison with standard of truth based on histopathology [abstract]. J Nucl Med. 2013;54(suppl 2):302.

6. Becker GA, Ichise $\mathrm{M}$, Barthel $\mathrm{H}$, et al. PET quantification of ${ }^{18} \mathrm{~F}$-florbetaben binding to beta-amyloid deposits in human brains. J Nucl Med. 2013;54: 723-731.

7. Landau SM, Breault C, Joshi AD, et al. Amyloid-beta imaging with Pittsburgh compound B and florbetapir: comparing radiotracers and quantification methods. J Nucl Med. 2013;54:70-77.

8. Lopresti BJ, Klunk WE, Mathis CA, et al. Simplified quantification of Pittsburgh compound B amyloid imaging PET studies: a comparative analysis. J Nucl Med. 2005;46:1959-1972.

9. Price JC, Klunk WE, Lopresti BJ, et al. Kinetic modeling of amyloid binding in humans using PET imaging and Pittsburgh compound-B. J Cereb Blood Flow Metab. 2005;25:1528-1547.

10. Mourik JE, Lubberink M, Schuitemaker A, et al. Image-derived input functions for PET brain studies. Eur J Nucl Med Mol Imaging. 2009;36:463-471.

11. Tolboom N, Yaqub M, Boellaard R, et al. Test-retest variability of quantitative $\left[{ }^{11} \mathrm{C}\right] \mathrm{PIB}$ studies in Alzheimer's disease. Eur J Nucl Med Mol Imaging. 2009;36: 1629-1638.

12. Su Y, Blazey TM, Owen CJ, et al. Quantitative amyloid imaging in autosomal dominant Alzheimer's disease: results from the DIAN study group. PLoS One. 2016;11:e0152082.

13. Zwan MD, Ossenkoppele R, Tolboom N, et al. Comparison of simplified parametric methods for visual interpretation of ${ }^{11} \mathrm{C}$-Pittsburgh compound-B PET images. J Nucl Med. 2014;55:1305-1307.

14. Mintun MA, Larossa GN, Sheline YI, et al. $\left[{ }^{11} \mathrm{C}\right] \mathrm{PIB}$ in a nondemented population: potential antecedent marker of Alzheimer disease. Neurology. 2006;67: 446-452.

15. Schmidt ME, Chiao P, Klein G, et al. The influence of biological and technical factors on quantitative analysis of amyloid PET: points to consider and recommendations for controlling variability in longitudinal data. Alzheimers Dement. 2015;11:1050-1068.
16. Villemagne VL, O'Keefe G, Mulligan RS, Rowe CC. Quantitative approaches to amyloid imaging. Methods Mol Biol. 2011;680:201-225.

17. Carrillo MC, Rowe CC, Szoeke C, et al. Research and standardization in Alzheimer's trials: reaching international consensus. Alzheimers Dement. 2013;9: 160-168.

18. Klunk WE, Koeppe RA, Price JC, et al. The Centiloid Project: standardizing quantitative amyloid plaque estimation by PET. Alzheimers Dement. 2015;11: $1-15$.

19. Villemagne VL, Burnham S, Bourgeat P, et al. Amyloid beta deposition, neurodegeneration, and cognitive decline in sporadic Alzheimer's disease: a prospective cohort study. Lancet Neurol. 2013;12:357-367.

20. Jack CR Jr, Wiste HJ, Lesnick TG, et al. Brain beta-amyloid load approaches a plateau. Neurology. 2013;80:890-896.

21. Juréus A, Swahn BM, Sandell J, et al. Characterization of AZD4694, a novel fluorinated Abeta plaque neuroimaging PET radioligand. J Neurochem. 2010;114: $784-794$.

22. Sundgren-Andersson AK, Svensson SPS, Swahn BM, et al. AZD4694: fluorinated positron emission tomography (PET) radioligand for detection of beta-amyloid deposits [abstract]. Alzheimers Dement. 2009;5(4, suppl 1): P267-P268.

23. Cselényi Z, Jonhagen ME, Forsberg A, et al. Clinical validation of ${ }^{18} \mathrm{~F}-\mathrm{AZD} 4694$, an amyloid-beta-specific PET radioligand. J Nucl Med. 2012;53:415-424.

24. Rowe CC, Pejoska S, Mulligan RS, et al. Head-to-head comparison of ${ }^{11} \mathrm{C}-\mathrm{PiB}$ and ${ }^{18} \mathrm{~F}-\mathrm{AZD} 4694$ (NAV4694) for beta-amyloid imaging in aging and dementia. J Nucl Med. 2013;54:880-886.

25. Vandenberghe $\mathrm{R}$, Van Laere $\mathrm{K}$, Ivanoiu $\mathrm{A}$, et al. ${ }^{18} \mathrm{~F}$-flutemetamol amyloid imaging in Alzheimer disease and mild cognitive impairment: a phase 2 trial. Ann Neurol. 2010;68:319-329.

26. Wong DF, Rosenberg PB, Zhou Y, et al. In vivo imaging of amyloid deposition in Alzheimer disease using the radioligand ${ }^{18} \mathrm{~F}-\mathrm{AV}-45$ (florbetapir [corrected] F 18). J Nucl Med. 2010;51:913-920. 